\title{
Presencia de gas en estructuras vasculares venosas encefálicas como hallazgo incidental en tomografía computada de encéfalo en ausencia de trauma
}

\author{
Cristóbal Bravo $C^{1}$, Jorge Cordovez M', Cecilia Okuma P', Evelyng Faure L', Marcelo Gálvez M'.
}

1. Neurorradiólogo, Departamento de Diagnóstico por Imágenes, Clínica Las Condes. Santiago, Chile.

Presence of gas in encephalic vascular venous structures as an incidental finding in brain computed tomography in the absence of trauma

\begin{abstract}
The presence of gas in the cerebral vascular venous structures is a finding that we infrequently see in our specialty. On many occasions we cannot pinpoint the cause, alarming the clinician, suggesting unnecessary exams, hospitalizations and controls. We performed a review of the literature and a retrospective study with the cases that we have reported in computed tomography of the brain in our radiology service, from January 2010 to July 2017.

Key words: intravenous air embolism, cerebral venous gas embolism, cerebral venous air embolism.
\end{abstract}

Resumen. La presencia de gas en las estructuras vasculares venosas cerebrales es un hallazgo que vemos infrecuentemente en nuestra especialidad. En muchas ocasiones no podemos precisar la causa, alarmando al clínico, sugiriendo exámenes, hospitalizaciones y controles innecesarios. Realizamos una revisión de la literatura y un trabajo retrospectivo con los casos que hemos reportado en tomografías computadas de encéfalo en nuestro servicio de radiología, desde enero del 2010 a julio del 2017.

Palabras clave: Embolia aérea intra venosa, embolia gaseosa venosa cerebral, embolia aérea venosa cerebral.

Bravo C., et al. Presencia de gas en estructuras vasculares venosas encefálicas como hallazgo incidental en tomografía computada de encéfalo en ausencia de trauma. Rev Chil Radiol 2017; 23(3): 106-108.

Correspondencia: Cristóbal Bravo / cabravoc@gmail.com

Trabajo recibido el 30 de agosto de 2017. Aceptado para publicación el 25 de septiembre de 2017.

\section{Introducción}

La presencia de gas en las estructuras vasculares venosas cerebrales es un hallazgo infrecuente en nuestra práctica radiológica al informar tomografías computadas encefálicas. Sin embargo, no necesariamente corresponde a un hallazgo patológico, ya que el organismo tiene la capacidad de manejar cantidades bajas de gas a nivel vascular, las cuales no determinan sintomatología ni presentan repercusiones en el paciente, siendo la causa más frecuente la introducción de gas a través de punciones venosas para la administración de suero o medicamentos.

Existen múltiples reportes en la literatura de los riesgos de la presencia de gas a nivel vascular, tanto venoso como arterial, con recomendaciones para el diagnóstico, observación y manejo.

En nuestro departamento por imágenes es un hallazgo que no ha generado complicaciones en nuestros pacientes.

A continuación, presentamos una revisión de los casos en que se ha diagnosticado la presencia de gas en estructuras vasculares venosas cerebrales y cervicales descritas en tomografía computada de encéfalo en nuestro departamento por imágenes.

\section{Material y método}

Se revisaron en forma retrospectiva las tomografías computadas de encéfalo realizadas en nuestro departamento por imágenes entre enero del año 2010 y julio del 2017, en las que se visualizó la presencia de gas en alguna de las estructuras vasculares venosas encefálicas o cervicales.

\section{Resultados}

Entre el primero de enero del 2010 y el 31 de julio del 2017 se realizaron 43.106 tomografías computadas de encéfalo en nuestro departamento por imágenes, de las cuales se encontraron 40 pacientes en que se informó la presencia de gas en alguna de las estructuras vasculares venosas encefálicas o cervicales en 
ausencia de trauma, lo que corresponde a un $0.09 \%$ de los pacientes evaluados (Figuras 1, 2, 3, 4, 5).

El lugar más frecuente de visualización de gas fue en los senos cavernosos, el cual se encontró en 35 de los 40 pacientes ( $87.5 \%$ ), (Figuras 4 y 5). Once de los pacientes presentaron gas en más de una ubicación (27.5\%) (Figuras 2 y 3 ). Siete pacientes presentaron gas en situación extracraneana (17.5\%) (Figuras 1, 2 y 3 ).

Ninguno de nuestros pacientes presentó sintomatología que fuera explicada por la presencia de gas, ni alteraciones secundarias a embolia aérea en el seguimiento.

\section{Discusión}

La presencia de gas en las estructuras vasculares venosas encefálicas o cervicales es un hallazgo que

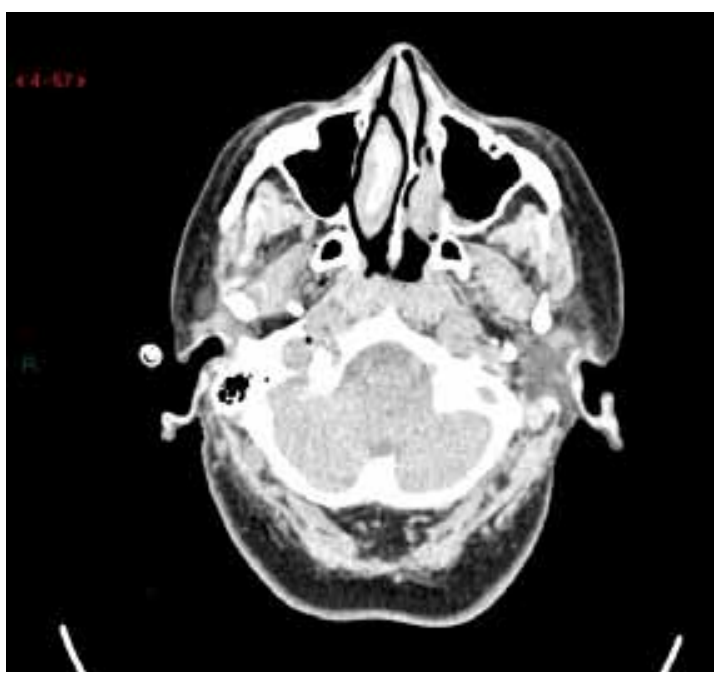

Figura 2. Gas en estructuras vasculares venosas intra y extra-raquídeas.

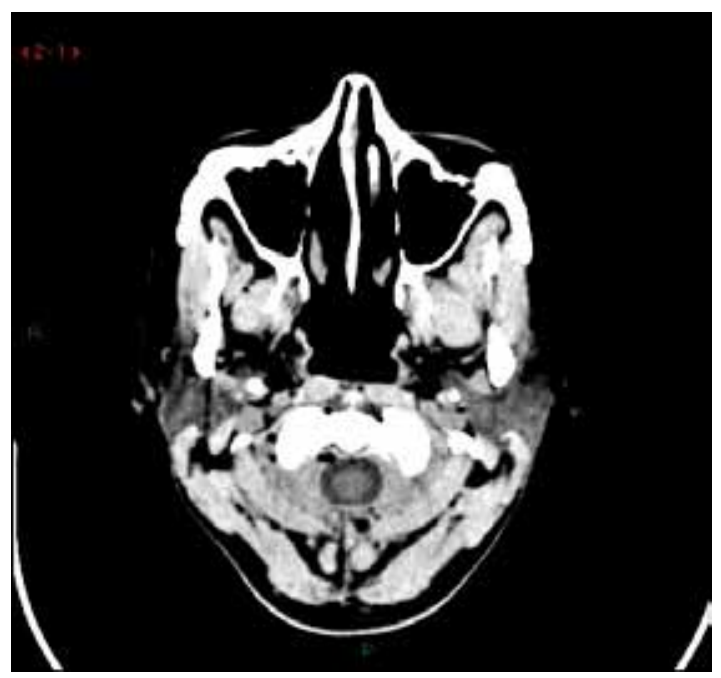

Figura 1. Gas en vena yugular derecha.

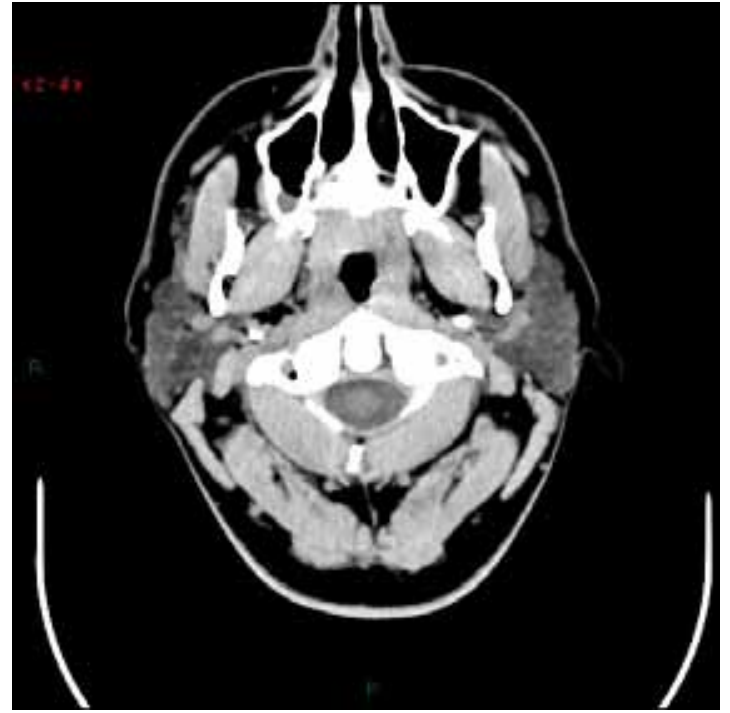

Figura 3. Gas en el plexo venoso vertebral derecho.

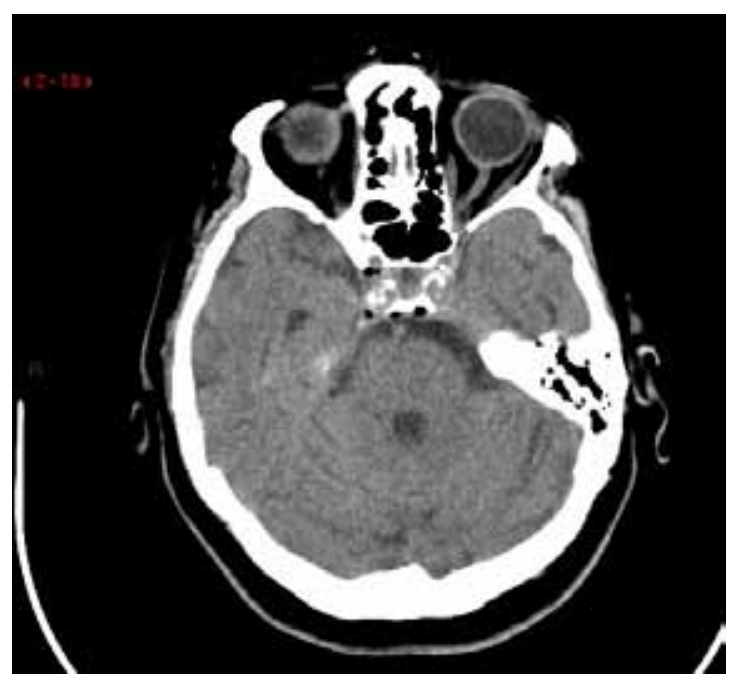

Figura 4. Gas en estructuras vasculares venosas adyacente al dorso de la silla turca y en seno cavernoso derecho.

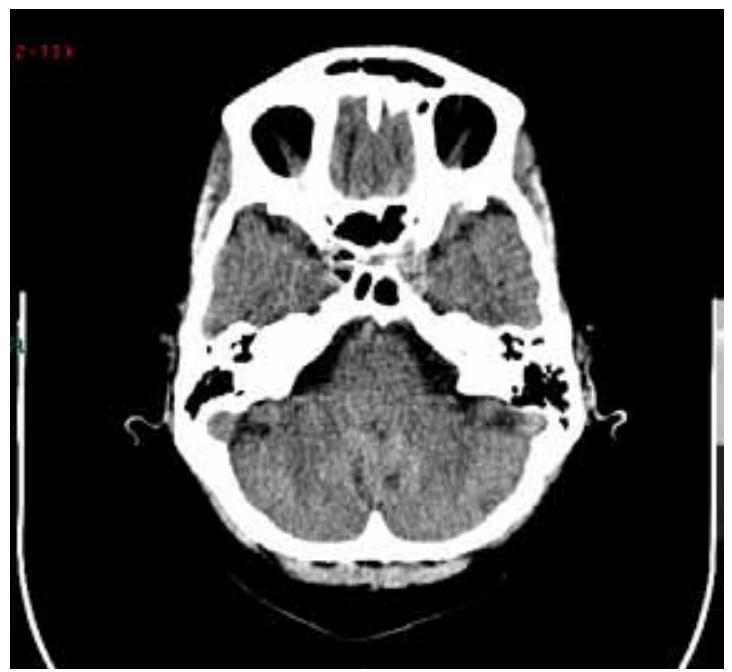

Figura 5. Gas en seno cavernoso derecho. 
vemos infrecuentemente en nuestra práctica radiológica rutinaria en tomografías computadas de encéfalo.

Esto corresponde a un hallazgo sin repercusión clínica, ya que nuestro organismo tiene la capacidad de manejar cantidades relativamente bajas de gas a nivel vascular venoso, permitiendo su eliminación a nivel capilar.

La causa más frecuente es secundaria a la introducción de gas a través de punciones venosas para la administración de suero o medicamentos ${ }^{1-4}$.

Existen múltiples reportes en la literatura de los riesgos de la presencia de gas a nivel vascular, tanto venoso como arterial, con recomendaciones para el diagnóstico, observación y manejo $0^{1-4}$.

Estudios animales sugieren que la entrada de gas venoso en un volumen mayor a $20 \mathrm{ml}$ o en volúmenes pequeños, pero continuos de aproximadamente 11 $\mathrm{ml} / \mathrm{min}$ pueden generar burbujas de aire arteriales ${ }^{1}$.

Creemos que la presencia de bajas cantidades de gas a nivel venoso en tomografía computada de encéfalo debiera ser descrito en nuestros informes radiológicos, dando a conocer que probablemente su origen se deba a la realización de una punción venosa antes del examen, además de dar a conocer que no corresponde a un hallazgo patológico con repercusión clínica. Esto evitará la realización de exámenes anexos en busca de su causa, evitará irradiar innecesariamente a los pacientes al controlar este gas mediante una nueva tomografía computada y evitará la realización de resonancia magnética de encéfalo en busca de consecuencias que pueda generar este hallazgo. Así evitaremos hospitalizaciones, gastos monetarios y gastos de personal innecesarios.

\section{Conclusión}

La presencia de gas a nivel vascular venoso encefálico es un hallazgo infrecuente en nuestra práctica clínica, que cuando se visualiza generalmente se ubica a nivel de los senos cavernosos. No corresponde a un hallazgo patológico y no tiene repercusión clínica evidente, por lo que no debemos alarmar a los clínicos, no siendo necesario la realización de exámenes anexos, ni el control tomográfico.

\section{Referencias}

1. Alzérreca E., Bahamonde H. Embolia gaseosa orbitaria y paraselar: Reporte de un caso. Rev. Otorrinolaringol Cir Cabeza Cuello 2012 Abr [citado 2017 Sep 14]; 72(1): 75-78.

2. Cabrerizo-Garcia JL., Zalba-Etayo B., Martin-Villen L. Embolismo gaseoso arterial cerebral y coronario.Rev Méd Chile, Santiago 2010; 138(11): 1461-146.

3. Claus M., Erik S. Gas Embolism. N Engl J Med 2000; 342: 476-482.

4. Voorhies RM., Fraser RAR. Cerebral air embolism occurring at angiography and diagnosed by computerized tomography. J Neurosurg 1984; 60: 177-178. 